\title{
An Antenna For UWB and Bluetooth Standards with Band-Notched Characteristic
}

\author{
Y. F. Weng, S. W. Cheung and T. I. Yuk \\ Department of Electrical and Electronic Engineering \\ The University of Hong Kong \\ Hong Kong \\ E-mail: [yfweng, swcheung, tiyuk]@eee.hku.hk
}

\begin{abstract}
This paper presents the design and results of a small size, integrated Bluetooth and Ultrawideband (UWB) planar monopole antenna with a band-notched characteristic in the WLAN band. The antenna consists of a dual-ring radiator as the primary radiation element for the Bluetooth and UWB bands and a complementary split-ring resonator (CSRR) to produce a notched characteristic at the center frequency of $5.5 \mathrm{GHz}$. The return loss, voltage-standing-wave ratio (VSWR), radiation pattern and peak gain of the antenna are studied by computer simulation and verified by measurements which agree well with the simulation results.
\end{abstract}

Index Terms-Dual ring, planar monopole antenna, Bluetooth, ultrawideband (UWB) antenna, band notched.

\section{INTRODUCTION}

Ultrawideband (UWB) communication system has the advantages of high data rate (more than $100 \mathrm{Mb} / \mathrm{s}$ ) for short ranges, easy connection and data exchange among a large number of multimedia devices such as PCs, high-definition TVs, digital cameras, etc. and so is attracting considerable interests in the recent years. The US-FCC has assigned the frequency band of 3.1-10.6 GHz for UWB systems and this has brought many opportunities and challenges to the antenna designers [1].

Over the past years, Bluetooth has been widely equipped in portable devices such as mobile phones, PDAs and notebooks, etc. In 2006, the Bluetooth Special Interest Group selected Multi-Band Orthogonal Frequency Division Multiplexing (MB-OFDM) version of UWB to integrate with the current Bluetooth wireless technology [2]. However, some portable devices such as notebooks have already embedded with three antennas, two of them for the wireless local area network (WLAN) in different frequency bands and the other one for the current Bluetooth system. These have already occupied quite a bit of space on the wireless devices. Moreover, consumers usually prefer lighter and thinner products, so putting an additional UWB antenna in a smaller wireless device is therefore a problem. One of the solutions is to have a single antenna to work in both the $2.4 \mathrm{GHz}$ Bluetooth band and the UWB band, yet without compromising the performance.

In the US-FCC allocation of frequency band for UWB applications, there are already several other existing communication systems, e.g. the IEEE 802.11a WLAN in the frequency band of $5.15-5.825 \mathrm{GHz}$, which may potentially interfere with the UWB systems. Thus UWB antennas with band-notched characteristic can be used to ease this potential problem [3]. Different antenna design methods have been proposed to produce the band-notched characteristic in the UWB band [3-8]. Among these methods, etching different kinds of slots on the patch or ground of the antennas is most often used [4-6]. Other methods to realize the notched band characteristic include adding parasitic elements and using fooled strips to the antennas [7]. However, the split-ring resonator (SRR) and complementary split-ring resonator (CSRR) are the most promising candidates to effectively filter the undesired signals in the UWB bands [3,8] and is the approach proposed here.

In this paper, we propose a small size planar monopole antenna that covers both the Bluetooth band and the UWB band, but exhibits a band-notched characteristic at the center frequency of $5.5 \mathrm{GHz}$. The antenna consists of a dual-ring radiator as the primary radiation element for Bluetooth and UWB bands operations and a CSRR to realize a notch at the center frequency of the $5.5 \mathrm{GHz}$ WLAN band. The antenna is studied by means of computer simulation and measurements. Results show that the radiation pattern is almost omnidirectional below $5 \mathrm{GHz}$ and only slightly directional at higher frequencies of the UWB band.

\section{STRUNCTURE AND DESIGN OF ANTENNA}

\section{Structure of antenna}

In our design, we propose to use a compact planar monopole geometry with a microstrip feeding line in order to minimize the antenna size for applications in wireless devices. Figure 1 shows the layout of our design which is fabricated on a Rogers PCB, RO4350B, with a transverse dimension of 40 $\mathrm{mm} \times 46 \mathrm{~mm}$ and having a relative dielectric constant $\varepsilon_{r}=$ 3.48, thickness $0.762 \mathrm{~mm}$ and loss tangent 0.0037 for the substrate. A rectangular shape, indicated as the dotted area in Fig. 1, is etched on the bottom plate of the substrate and serves as ground of the antenna. The distance between the top edge of the ground plate and the circumference of the circular radiator, denoted as $L_{g a p}$ in Fig. 1, is used to tune the resonance frequency and adjust the input impedance of the antenna and hence plays a very important role in the design of the antenna. The primary radiating element of the antenna is a dual-ring structure, formed by an outer ring and inner ring, as shown in Fig. 1. There is no ground metallization underneath the radiator. 
SRR, originally proposed by Pendry [9], is a small size resonator with a very high Q [10] and hence can be used to produce a band-notch characteristic in a planar antenna [11]. A SRR consisting of a pair of concentric annular rings with splits at the opposite ends was considered in our design to implement the band-notch characteristic of the antenna. To minimize the size of our design, we had considered placing the SRR element on the outer ring of the dual ring. However, this would not be possible due to the existing copper material of the ring. Since the behaviour of a slotted CSRR is similar to that of the SRR, we propose to use a CSRR, instead of SRR, and place it on the outer ring of our design as shown in Fig.1.

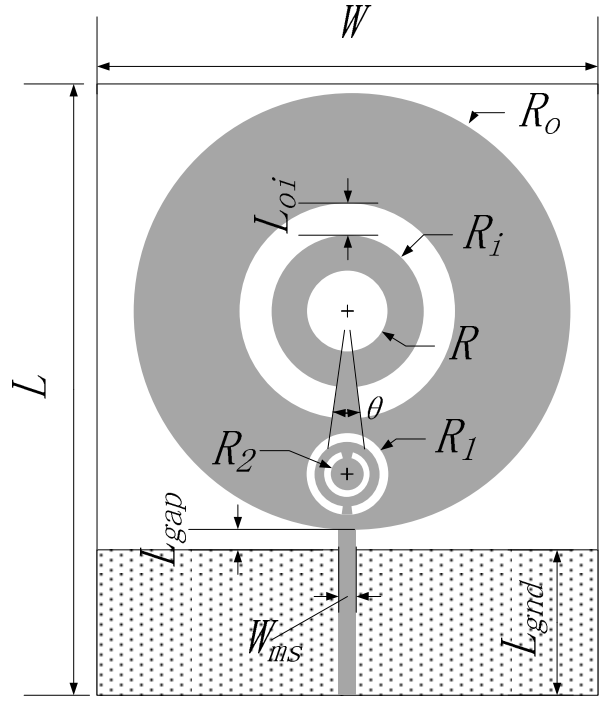

(a)

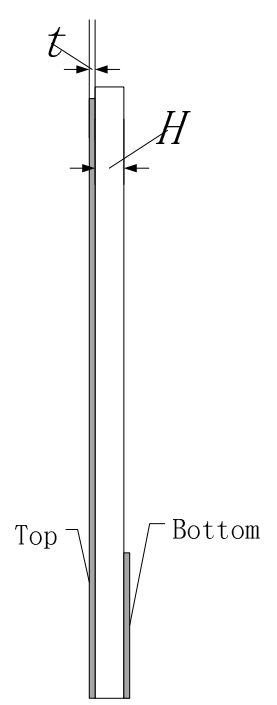

(b)
Fig. 1. Layout of antenna: (a) top view and (b) side view.

\section{Design of antenna}

The design of the antenna is carried out by using the EM software CST MWS 2009 [12]. With the use of a relative dielectric constant $\varepsilon_{r}=3.48$ and thickness $0.762 \mathrm{~mm}$ for the substrate of the $\mathrm{PCB}$, we can calculate the required width $W_{m s}=1.5 \mathrm{~mm}$ of the microstrip feeding line to the radiator for a characteristic impedance of $50 \Omega$ [13] and this is used as the starting point of our design.

The next step is the calculation of the outer radius $R_{o}$ which affects the lowest operation frequency of the antenna. The dimension of $R_{o}$ for the lowest operation of frequency $f_{1}$ can be approximated by [14]:

$$
\begin{aligned}
& R_{o} \approx c / 4 \sqrt{\varepsilon_{e f f}} f_{l} \approx \lambda_{e f f} / 4 \\
& \varepsilon_{e f f} \approx\left(\varepsilon_{r}+1\right) / 2
\end{aligned}
$$

where $c, \varepsilon_{\text {eff }}$ and $\lambda_{\text {eff }}$ are the speed of light in free space, the effective dielectric constant and the effective wavelength for the radiation mode in the substrate with a relative dielectric constant $\varepsilon_{r}=3.48$, respectively. With $f_{1}=2.3 \mathrm{GHz}$, we can use Eq. 1 to calculate the initial value of $R_{o}$.

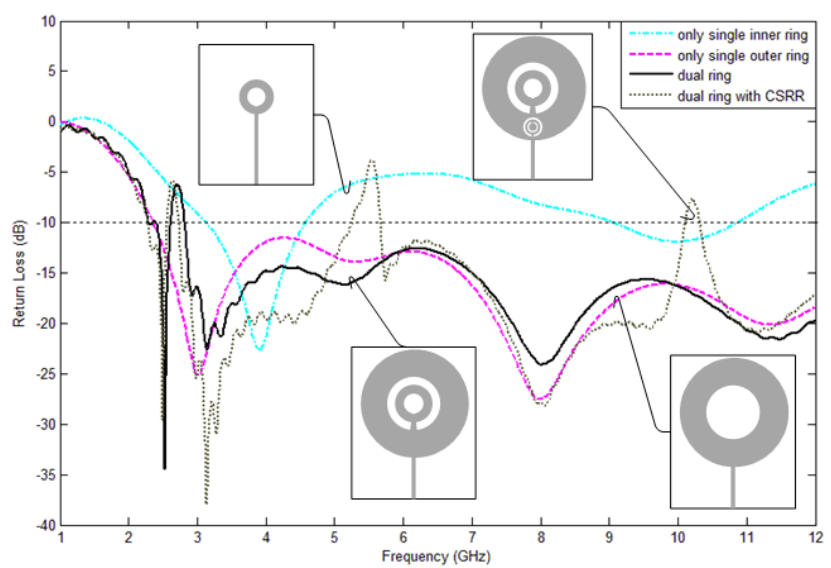

Fig. 2. Simulated Return Losses of dual ring, outer ring and inner ring without CSRR, and dual ring with CSRR. $W_{m s}=1.2 \mathrm{~mm}, L_{\text {gap }}=1.1 \mathrm{~mm}, R_{o}=16.5$ $\mathrm{mm}, R_{i}=6.5 \mathrm{~mm}, \theta=12^{\circ}, L_{o i}=2.5 \mathrm{~mm}, R=3 \mathrm{~mm}$ and $L_{g n d}=12 \mathrm{~mm}$.

With the use of the calculated values $W_{m s}$ and $R_{o}$ and the optimization criteria of having reasonable return loss values (less than $-10 \mathrm{~dB}$ ) across the UWB band and a resonant frequency at the Bluetooth frequency of $2.45 \mathrm{GHz}$, the EM software CST MWS 2009 is used to optimize all parameter values, including $W_{m s}$ and $R_{o}$. Results have shown that the optimum values are $W_{m s}=1.2 \mathrm{~mm}, L_{\text {gap }}=1.1 \mathrm{~mm}, R_{o}=16.5$ $\mathrm{mm}, R_{i}=6.5 \mathrm{~mm}, \theta=12^{\circ}, L_{o i}=2.5 \mathrm{~mm}, R=3 \mathrm{~mm}$ and $L_{\text {gnd }}=12 \mathrm{~mm}$. With these optimized values, the return loss of the dual ring is shown in Fig. 2. To see the effects of individual rings in the dual ring, the return losses of only outer ring and only the inner ring are also shown in the same figure for comparison. It can be seen that, for the outer ring alone, the return losses are less than $-10 \mathrm{~dB}$ for the whole UWB frequency band from $3.1 \mathrm{GHz}$ to $10.6 \mathrm{GHz}$. For the inner ring alone, the return losses are less than $-10 \mathrm{~dB}$ only from 3.13 $\mathrm{GHz}$ to $4.58 \mathrm{GHz}$ and larger $-10 \mathrm{~dB}$ for most of the rest of the UWB band. However, when the two rings are combined together to form a dual ring, there are two frequency bands which have return losses of less than $-10 \mathrm{~dB}$, i.e., from 2.298 $\mathrm{GHz}$ to $2.602 \mathrm{GHz}$ and also from $2.804 \mathrm{GHz}$ to $12 \mathrm{GHz}$. This is due to the coupling properties between these two rings.

From simulation, it is also found that two pivotal parameters, $L_{o i}$ (the distance between the outer ring and the inner ring) and $\theta$ (the angle of the inner feed sector) as shown in Fig. 1, play an important role in tuning the minimum return loss across the UWB band and so can be used to tune it to the Bluetooth band. Figures 3 and 4 show the simulated return losses with different values of $L_{o i}$ and $\theta$, respectively. It can be seen that the resonant frequency in the Bluetooth band 
varies with $L_{o i}$ and $\theta$, yet the return losses across the UWB band remaining about the same. Thus, we can tune the frequency with minimum return loss to $2.45 \mathrm{GHz}$ in the Bluetooth band by using $\theta$ and $L_{o i}$, while keeping the return losses across the UWB about the same. Results from simulation have shown that, with $\theta=12^{\circ}$ and $L_{o i}=2.5 \mathrm{~mm}$, the return loss is minimum at $2.45 \mathrm{GHz}$ in the Bluetooth band as shown in Fig. 2.

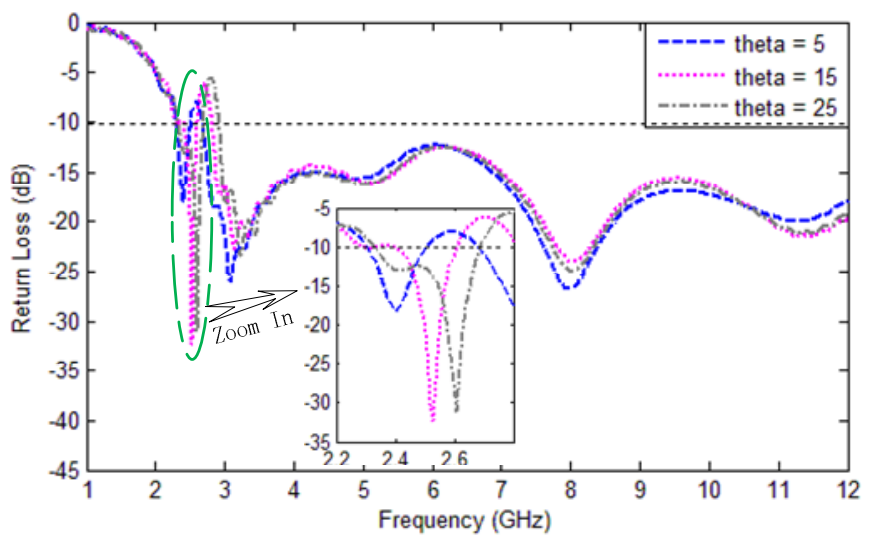

Fig. 3. Return losses for different values of $\theta . W_{m s}=1.2 \mathrm{~mm}, L_{g a p}=1.1 \mathrm{~mm}$, $R_{o}=16.5 \mathrm{~mm}, R_{i}=6.5 \mathrm{~mm}, L_{o i}=2.5 \mathrm{~mm}, R=3 \mathrm{~mm}$ and $L_{g n d}=12 \mathrm{~mm}$.

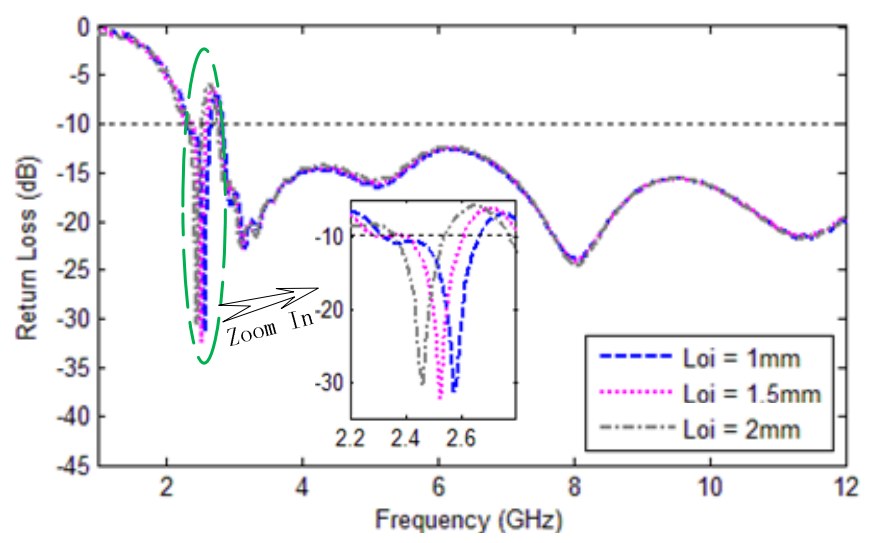

Fig. 4. Return losses with frequency for different values of $L_{o i} . W_{m s}=1.2 \mathrm{~mm}$, $L_{\text {gap }}=1.1 \mathrm{~mm}, R_{o}=16.5 \mathrm{~mm}, R_{i}=6.5 \mathrm{~mm}, \theta=12^{\circ}, R=3 \mathrm{~mm}, L_{\text {gnd }}=12$ $\mathrm{mm}$.

The typical structures of SRR and CSRR are shown in Figs. 5(a) and 5(b), respectively. A SRR behaves like a LC resonator at the resonant frequency [15]:

$$
\omega_{0}=\sqrt{\frac{2}{\pi r L C_{0}}}
$$

where $r=\left(r_{1}+r_{2}\right) / 2$ is the average radius of the SRR, $L$ is the total inductance of the SRR, and $C_{o}$ is the per unit length capacitance between the two rings [15]. A SRR is used to implement the band-notched characteristic at $5.5 \mathrm{GHz}$ in our design. To reduce the size of the antenna, a corresponding CSRR is proposed to be used instead and placed inside the outer ring with the split facing the feeding line as shown in Fig. 1. It should be noted that Eq. (3) only provides a coarse estimate of the dimensions for the CSRR, so simulation has been used for optimization. Simulation results have shown the optimum dimensions are $r_{1}=3.3 \mathrm{~mm}, r_{2}=1.4 \mathrm{~mm}, r=2.35$ $\mathrm{mm}, c=0.6 \mathrm{~mm}, d=0.7 \mathrm{~mm}$. With the use of these optimized values, the simulated return loss of the antenna is shown in Fig. 2. It can be seen that the return loss of our design is the lowest in the frequencies around $5.5 \mathrm{GHz}$.

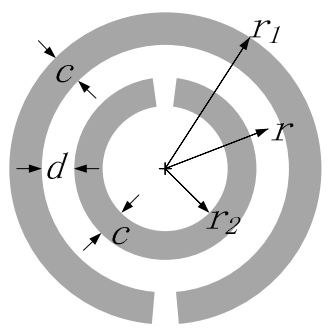

(a)

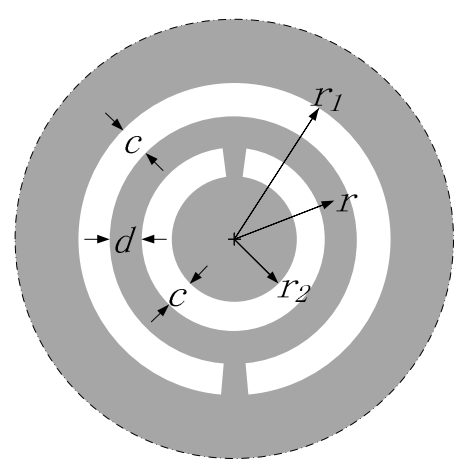

(b)
Fig. 5 Typical SRR and CSRR elements: (a) SRR and (b) CSRR.

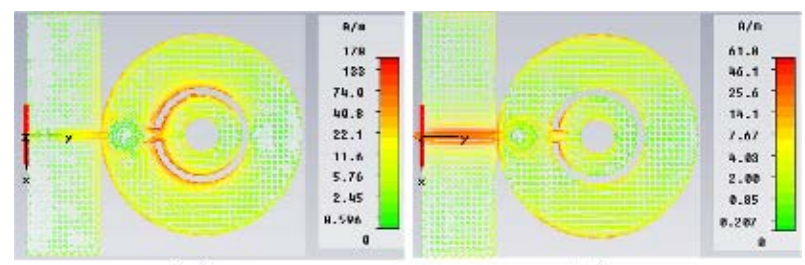

(a)

(b)

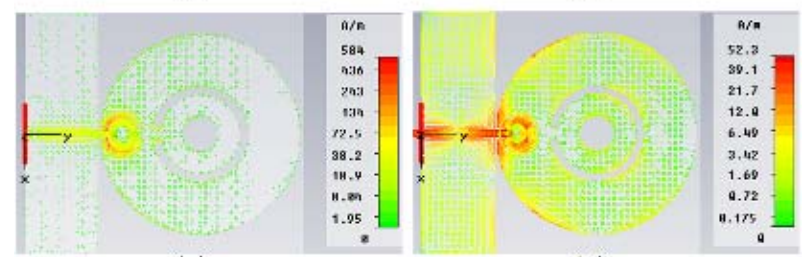

(c)

(d)

Fig. 6. Distribution of surface current at (a) $2.45 \mathrm{GHz}$, (b) $4.5 \mathrm{GHz}$, (c) $5.5 \mathrm{GHz}$ and (d) $8 \mathrm{GHz}$, with $W_{m s}=1.2 \mathrm{~mm}, L_{g a p}=1.1 \mathrm{~mm}, R_{o}=16.5 \mathrm{~mm}, R_{i}=6.5$ $\mathrm{mm}, \theta=12^{\circ}, R=3 \mathrm{~mm}, L_{g n d}=12 \mathrm{~mm}, L_{o i}=2.5 \mathrm{~mm}, R_{1}=3.3 \mathrm{~mm}$ and $R_{2}$ $=1.4 \mathrm{~mm}$.

We have also studied the distributions of surface current in the antenna at different frequencies in order to have better understanding of its operation. Figures 6(a) to 6(d) show the surface current distributions at $2.45 \mathrm{GHz}, 4.5 \mathrm{GHz}, 5.5 \mathrm{GHz}$ and $8 \mathrm{GHz}$, respectively. At the Bluetooth frequency of 2.45 GHz, Fig. 6(a) shows that the areas around the slot between the 
outer and inner rings are most active. This implies that the dimensions $L_{o i}$ and $\theta$ are critical for the characteristic of return loss near the Bluetooth frequency band. Figures 6(b) and 6(d) show that at $4.5 \mathrm{GHz}$ and $8 \mathrm{GHz}$, the current mainly exists at the edges of the rings. At the frequency of $5.5 \mathrm{GHz}$, Fig. 6(c) shows that the energy is confined in the CSRR element and much more than that in the main radiator of the antenna, so it does not get radiated.

\section{RESULTS AND DISCUSSIONS.}

The final design of the antenna with and without the CSRR element has been fabricated on a Rogers PCB, RO4305B, as shown in Fig. 7. The VSWR across the UWB band, the peak gains and the radiation patterns at $2.45 \mathrm{GHz}, 4.5 \mathrm{GHz}$ and 8 $\mathrm{GHz}$ have been simulated by using CST MWS 2009 and measured using the Satimo Starlab measurement system [16] for verification.

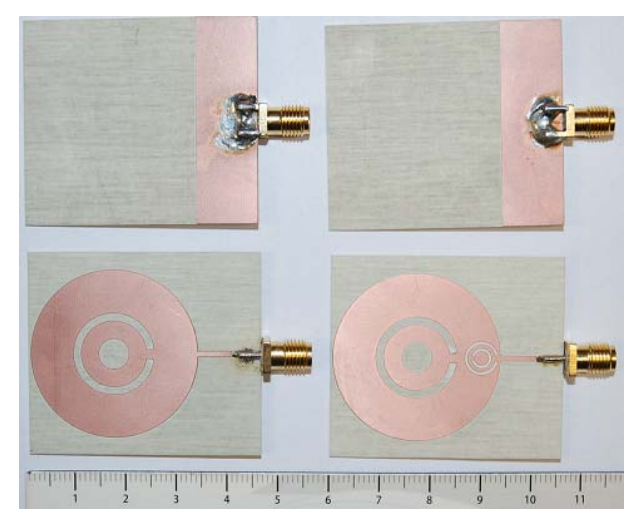

Fig. 7. Photograph of with and without CSRR antennas for study.

Figure 8 shows the simulated and measured VSWRs. With the CSRR element in place, the VSWR is substantially higher (VSWR>2) from $5.2 \mathrm{GHz}$ to $5.67 \mathrm{GHz}$, blocking the signals within the band without affecting the VSWR values in the rest of the UWB bands.

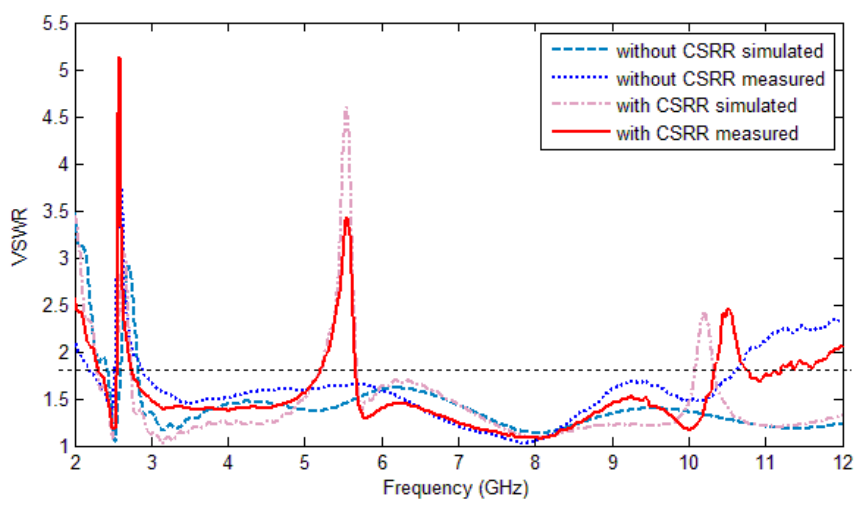

Fig. 8. Simulated and measured VSWR of antennas with and without CSRR.

The simulated and measured radiation patterns of the antenna with the CSRR element at the frequencies of 2.45
$\mathrm{GHz}, 4.5 \mathrm{GHz}$ and $8 \mathrm{GHz}$ in three important cuts, i.e., in the $\mathrm{x}-$ $\mathrm{z}, \mathrm{y}-\mathrm{z}, \mathrm{x}-\mathrm{y}$ planes, are shown in Fig. 9. It can be seen that the measured radiation patterns agree well with the simulated results. For UWB applications, omnidirectional radiation pattern is normally preferred (i.e., in the $x-y$ plane). The results of Fig. 9 show that the radiation patterns at both $2.45 \mathrm{GHz}$ and the $4.5 \mathrm{GHz}$ satisfy this requirement quite well. Since the ground is realized by a finite plane which is not perfect, this makes the radiation pattern slightly directional at $8 \mathrm{GHz}$.

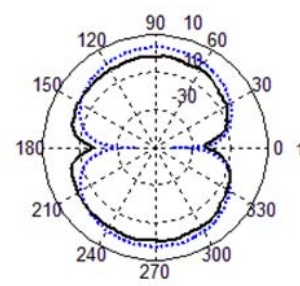

(a)

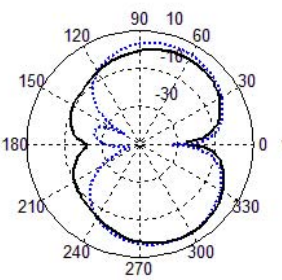

(d)

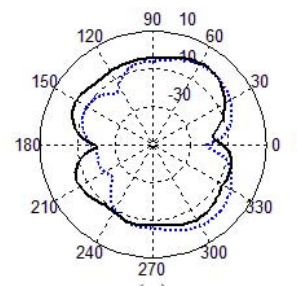

(g)

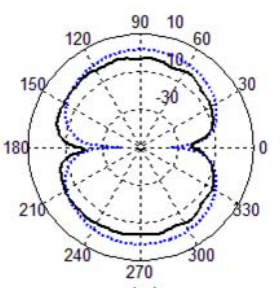

(b)

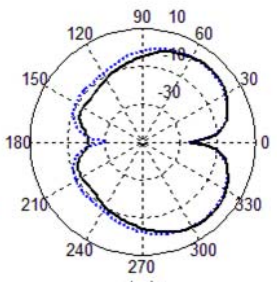

(e)

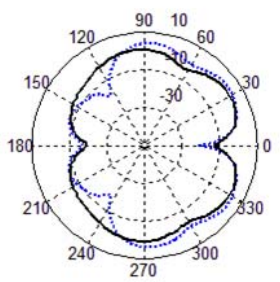

(h)

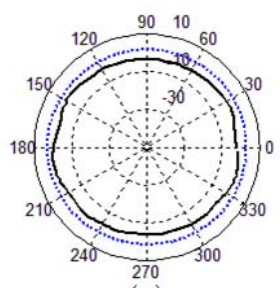

(c)

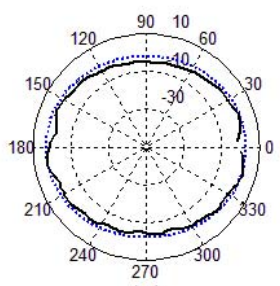

(f)

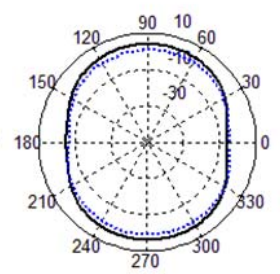

(i)

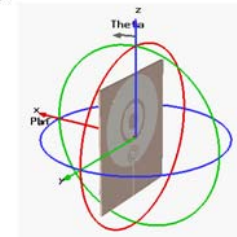

simulated radiation pattern measured radiation pattern

Fig. 9. Simulated and measured radiation patterns of antenna with CSRR element. Solid lines and dash lines are measured and simulated results, respectively. (a) $2.45 \mathrm{GHz}$ in $\mathrm{x}-\mathrm{z}$ plane; (b) $2.45 \mathrm{GHz}$ in $\mathrm{y}-\mathrm{z}$ plane; (c) 2.45 $\mathrm{GHz}$ in $\mathrm{x}-\mathrm{y}$ plane; (d) $4.5 \mathrm{GHz}$ in $\mathrm{x}-\mathrm{z}$ plane; (e) $4.5 \mathrm{GHz}$ in y-z plane; (f) 4.5 $\mathrm{GHz}$ in $\mathrm{x}-\mathrm{y}$ plane; $(\mathrm{g}) 8 \mathrm{GHz}$ in $\mathrm{x}-\mathrm{z}$ plane; (h) $8 \mathrm{GHz}$ in $\mathrm{y}-\mathrm{z}$ plane; and (i) 8 $\mathrm{GHz}$ in $\mathrm{x}-\mathrm{y}$ plane.

The measured and simulated results on the peak gains of the antenna, with and without the CSRR element, are shown in Fig. 10. In the measured results, the peak gain in the Bluetooth band is around $2 \mathrm{~dB}$. In the notched band, i.e., at around of $5.5 \mathrm{GHz}$, the peak gain drops by $4 \mathrm{~dB}$. The peak gains in the rest of the UWB band are between 2 to $6 \mathrm{~dB}$. 


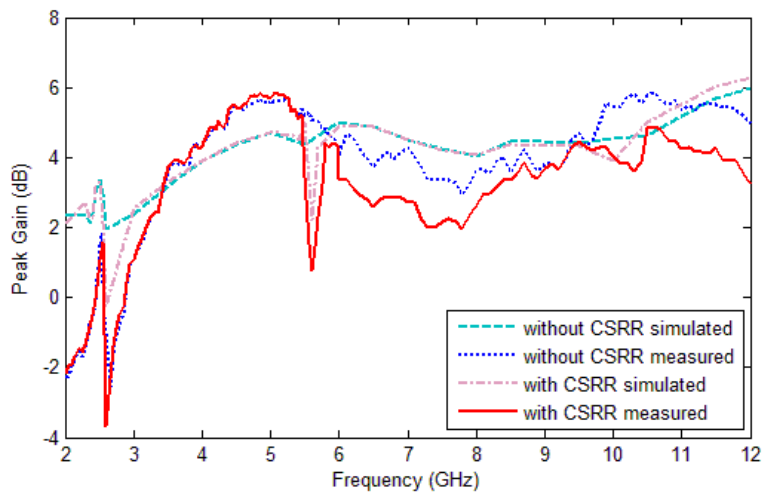

Fig. 10. Simulated and measured peak gain of antennas with and without CSRR.

\section{CONCLUSION}

In this paper, we have presented the design of a small size, planar monopole antenna that covers both the Bluetooth band and the UWB band, but exhibits a band-notched characteristic at the center frequency of $5.5 \mathrm{GHz}$. The antenna consists of a dual-ring structure as the primary radiation element, a CSRR element with a high quality factor to reject the $5.5 \mathrm{GHz}$ WLAN band and a slot between the outer and inner rings to achieve good impedance matching at the Bluetooth band. The dimensions of these elements have been examined and optimized using computer simulation. The final design has also been fabricated on a Rogers PCB and measured. Results have shown that the antenna is almost omnidirectional below $5 \mathrm{GHz}$ and slight directional at higher frequencies of the UWB band. The peak gain values at both the Bluetooth and UWB bands are satisfactory. Simulated and measured results have shown great agreements.

\section{REFERENCES}

[1] "Federal Communications Commission Revision of Part 15 of the Commission's Rules Regarding Ultra-Wideband Transmission Systems," FCC, 2002, First Report and Order FCC, 02.V48.
[2] "Bluetooth sig selects wimedia alliance ultra-wideband technology for high speed bluetooth applications," available on: http://www.bluetooth.com.

[3] Y. Zhang, W. Hong, C. Yu, Z-Q. Kuai, Y-D. Don and J-Y. Zhou, "Planar Ultrawideband Antennas With Multiple Notched Bands Based on Etched Slots on the Patch and/or Split Ring Resonators on the Feed Line," IEEE Trans. Antennas Propag, vol. 56, pp. 3063, Sep. 2008.

[4] A. Kerkhoff and H. Ling, "Design of a planar monopole antenna for use with ultra-wideband (UWB) having a band-notched characteristic,"in Proc. IEEE Antennas Propagation Society Int. Symp.,Columbus, OH, USA, vol. 1, pp. 830-833, 2003.

[5] W. Choi, K. Chung, J. Jung and J. Choi, "Compact ultra-wideband printed antenna with band-rejection characteristic," Electron. Lett., vol. 41, no. 18, pp. 990-991, Sep. 2005.

[6] K. Chawanonphithak, C. Phongcharoenpanich, S. Kosulvit and M.Krairiksh, "5.8 $\mathrm{GHz}$ notched UWB bidirectional elliptical ring antennaexcited by circular monopole with curved slot," in Proc. AsiaPacificMicrowave Conf., pp. 653-656, Dec. 2007.

[7] T. G. Ma and S. J. Wu, "Ultrawideband band-notched folded strip monopole antenna," IEEE Trans. Antennas Propag., vol. 55, no. 9, pp. 2473-2479, Sep. 2007.

[8] J. C. Ding, Z. L. Lin, Z. N. Ying and S. L. He, "A compact ultrawidebandslot antenna with multiple notch frequency bands," Microw. Opt. Technol. Lett., vol. 49, no. 12, pp. 3056-3060, Dec. 2007.

[9] J. B. Pendry, A. J. Holden, D. J. obbins and W. J. Stewart, "Magnetism from conductors and enhanced nonlinear phenomena," IEEE Trans. Microw. Theory Tech., vol. 47, pp. 2075-2084, 1999.

[10] J. Kim, C. S. Cho and J. W. Lee, "5.2 GHz notched ultra-wideband antenna using slot-type SRR," Electron. Lett., vol. 42, no. 6, pp. 315316, Mar. 2006.

[11] J.D. Baena, J. Bonache, F. Martin, R.M. Sillero, F. Falcone, T. Lopetegi, M.A.G. Laso, J. Garcia-Garcia, I. Gil, M.F. Portillo and M. Sorolla, "Equivalent-Circuit Models for Split-Ring Resonators and Complementary Split-Ring Resonators Coupled to Planar Transmission Lines," IEEE Trans. Theory Tech, vol. 53, no. 4, pp. 1451-1461, Apr. 2005 .

[12] Available on: http://www.cst.com

[13] D. Pozar, Microwave Engineering, $3^{\text {rd }}$ ed. New York: Wiley, 2005.

[14] C. Balanis, Antenna Theory; Analysis and Design, $3^{\text {rd }}$ ed. New York: Wiley, 2005.

[15] R. Marquès, F. Mesa, J. Martel and F. Medina, "Comparative analysis of edge-and broadside-coupled split ring resonators for metamaterial design-theory and experiments," IEEE Trans Antennas Propag. , vol 51, no 10, pp. 2572-2581, Oct. 2003.

[16] Available on: http://www.satimo.fr/eng/index.php?categoryid=141. 